\title{
Comparison of culture-negative and culture-positive sepsis or septic shock: a systematic review and meta-analysis
}

\author{
Yuting Li, Jianxing Guo, Hongmei Yang, Hongxiang Li, Yangyang Shen and Dong Zhang*
}

\begin{abstract}
Background: Mortality and other clinical outcomes between culture-negative and culture-positive septic patients have been documented inconsistently and are very controversial. A systematic review and meta-analysis was performed to compare the clinical outcomes of culture-negative and culture-positive sepsis or septic shock.

Methods: We searched the PubMed, Cochrane and Embase databases for studies from inception to the 1st of January 2021. We included studies involving patients with sepsis or septic shock. All authors reported our primary outcome of all-cause mortality and clearly compared culture-negative versus culture-positive patients with clinically relevant secondary outcomes (ICU length of stay, hospital length of stay, mechanical ventilation requirements, mechanical ventilation duration and renal replacement requirements). Results were expressed as odds ratio (OR) and mean difference (MD) with accompanying 95\% confidence interval (Cl).
\end{abstract}

Results: Seven studies including 22,655 patients were included. The primary outcome of this meta-analysis showed that there was no statistically significant difference in the all-cause mortality between two groups $(\mathrm{OR}=0.95 ; 95 \% \mathrm{Cl}$, 0.88 to $1.01 ; P=0.12 ; \mathrm{Chi}^{2}=30.71 ; P^{2}=80 \%$ ). Secondary outcomes demonstrated that there was no statistically significant difference in the ICU length of stay (MD $=-0.19 ; 95 \% \mathrm{Cl},-0.42$ to $0.04 ; P=0.10 ; \mathrm{Chi}^{2}=5.73 ; P^{2}=48 \%$ ), mechanical ventilation requirements $\left(\mathrm{OR}=1.02 ; 95 \% \mathrm{Cl}, 0.94\right.$ to $\left.1.11 ; P=0.61 ; \mathrm{Chi}^{2}=6.32 ; I^{2}=53 \%\right)$ and renal replacement requirements $\left(\mathrm{OR}=0.82 ; 95 \% \mathrm{Cl}, 0.67\right.$ to $\left.1.01 ; P=0.06 ; \mathrm{Chi}^{2}=1.21 ; P^{2}=0 \%\right)$ between two groups. The hospital length of stay of culture-positive group was longer than that of the culture-negative group ( $\mathrm{MD}=-3.48 ; 95 \% \mathrm{Cl},-4.34$ to $-2.63 ; P<0.00001 ; \mathrm{Chi}^{2}{ }^{2}=1.03 ; P^{2}=0 \%$ ). The mechanical ventilation duration of culture-positive group was longer than that of the culture-negative group ( $\mathrm{MD}=-0.64 ; 95 \% \mathrm{Cl},-0.88$ to $\left.-0.4 ; P<0.00001 ; \mathrm{Chi}^{2}=4.86 ; P^{2}=38 \%\right)$.

Conclusions: Culture positivity or negativity was not associated with mortality of sepsis or septic shock patients. Furthermore, culture-positive septic patients had similar ICU length of stay, mechanical ventilation requirements and renal replacement requirements as those culture-negative patients. The hospital length of stay and mechanical ventilation duration of culture-positive septic patients were both longer than that of the culture-negative patients. Further large-scale studies are still required to confirm these results.

Keywords: Culture-negative, Culture-positive, Sepsis, Septic shock, Clinical outcomes, Meta-analysis

*Correspondence: zhangdong@jlu.edu.cn

Department of Intensive Care Unit, The First Hospital of Jilin University,

Changchun 130021, Jilin, China permits use, sharing, adaptation, distribution and reproduction in any medium or format, as long as you give appropriate credit to the original author(s) and the source, provide a link to the Creative Commons licence, and indicate if changes were made. The images or other third party material in this article are included in the article's Creative Commons licence, unless indicated otherwise in a credit line to the material. If material is not included in the article's Creative Commons licence and your intended use is not permitted by statutory regulation or exceeds the permitted use, you will need to obtain permission directly from the copyright holder. To view a copy of this licence, visit http://creativecommons.org/licenses/by/4.0/. The Creative Commons Public Domain Dedication waiver (http://creativeco mmons.org/publicdomain/zero/1.0/) applies to the data made available in this article, unless otherwise stated in a credit line to the data. 


\section{Key messages}

- Culture positivity or negativity was not associated with mortality of sepsis or septic shock patients.

- Culture-positive septic patients had similar ICU length of stay, mechanical ventilation requirements and renal replacement requirements as those culturenegative patients.

- The hospital length of stay and mechanical ventilation duration of culture-positive septic patients were both longer than that of the culture-negative patients.

\section{Introduction}

The incidence of sepsis and septic shock has been increasing worldwide over the past decade, and its morbidity and mortality are still unacceptably high [1]. Mortality from sepsis and septic shock remains incredibly high, ranging between 20 and $40 \%$, depending on the severity of illness [2, 3]. Guidelines and protocols for sepsis and septic shock treatment have been published and modified over the past two decades. These guidelines widely recommend empirical application of broad-spectrum antibiotics, and several studies have demonstrated that time to effective antibiotic therapy reduces patient mortality [4].

According to The Third International Consensus Definitions for Sepsis and Septic Shock (Sepsis-3), sepsis was defined as life-threatening organ dysfunction caused by a dysregulated host response to infection. Patients with septic shock can be identified with a clinical construct of sepsis with persisting hypotension requiring vasopressors to maintain mean arterial pressure $(\mathrm{MAP}) \geq 65 \mathrm{~mm} \mathrm{Hg}$ and having a serum lactate level $>2 \mathrm{mmol} / \mathrm{L}(18 \mathrm{mg} / \mathrm{dL})$ despite adequate volume resuscitation [5]. Sepsis involves a wide array of sources and microorganisms, only a fraction of which are microbiologically documented. Sepsis/ septic shock without a microbiologically documented infection is called culture-negative sepsis/septic shock. Determination of culture-negative septic shock was based on the diagnosis of septic shock in the absence of positive pathogen cultures from blood, sputum, body fluids, or other tissues. Previous studies have shown that the proportion of culture-negative cases was between 28 and $49 \%$ of all patients with sepsis [6-8]. Culture-negative sepsis poses special diagnostic challenges to both clinicians and microbiologists and further questions the validity of sepsis definitions [9].

Sepsis or septic shock is a highly heterogeneous syndrome, affecting patients with various underlying conditions. The possibility exists that culture-negative cases may differ in fundamental ways from culture-positive sepsis or septic shock with respect to pathophysiology, epidemiology, and treatment responses [10]. Mortality and other clinical outcomes between culture-negative and culture-positive septic patients have been documented inconsistently and are very controversial. Therefore, we conducted a meta-analysis, which extracted results from published cohort studies to compare the clinical outcomes of culture-negative and culture-positive sepsis or septic shock.

\section{Methods}

This systematic review and meta-analysis is reported according to the Preferred Reporting Items for Systematic Reviews and Meta-Analyses (PRISMA) guidelines [11]. Ethical approval was not necessary for this study because it was a review of the published literature.

\section{Search strategy}

We searched the PubMed, Cochrane, and Embase databases for studies from inception to the 1st of January 2021 using the following search terms: culture-positive, culture-negative, sepsis, severe sepsis, septic shock. The search was slightly adjusted according to the requirements of the different databases. The authors' personal files and reference lists of relevant review articles were also reviewed. The flowchart of the search strategies is summarized in Fig. 1.

\section{Types of outcome measures}

The primary outcome was all-cause mortality, all-cause mortality included hospital mortality, 28-day mortality and 90-day mortality. Secondary outcomes were intensive care unit (ICU) length of stay, hospital length of stay, mechanical ventilation requirements, mechanical ventilation duration and renal replacement requirements. Weighted means were calculated based on the number of patients in each study.

\section{Study selection}

The inclusion criteria were as follows: (1) prospective and retrospective cohort studies; (2) patients with sepsis or septic shock; (3) all authors reported our primary outcome of all-cause mortality; (4) clearly comparing culture-negative versus culture-positive patients with clinically relevant secondary outcomes. We excluded studies including not estimable data [12] and without clear comparisons of the outcomes. In addition, we excluded letter and review.

\section{Quality assessment}

Two reviewers (YL and JG) independently performed quality assessment. The quality of studies was assessed using the Newcastle-Ottawa scale (NOS) for cohort 

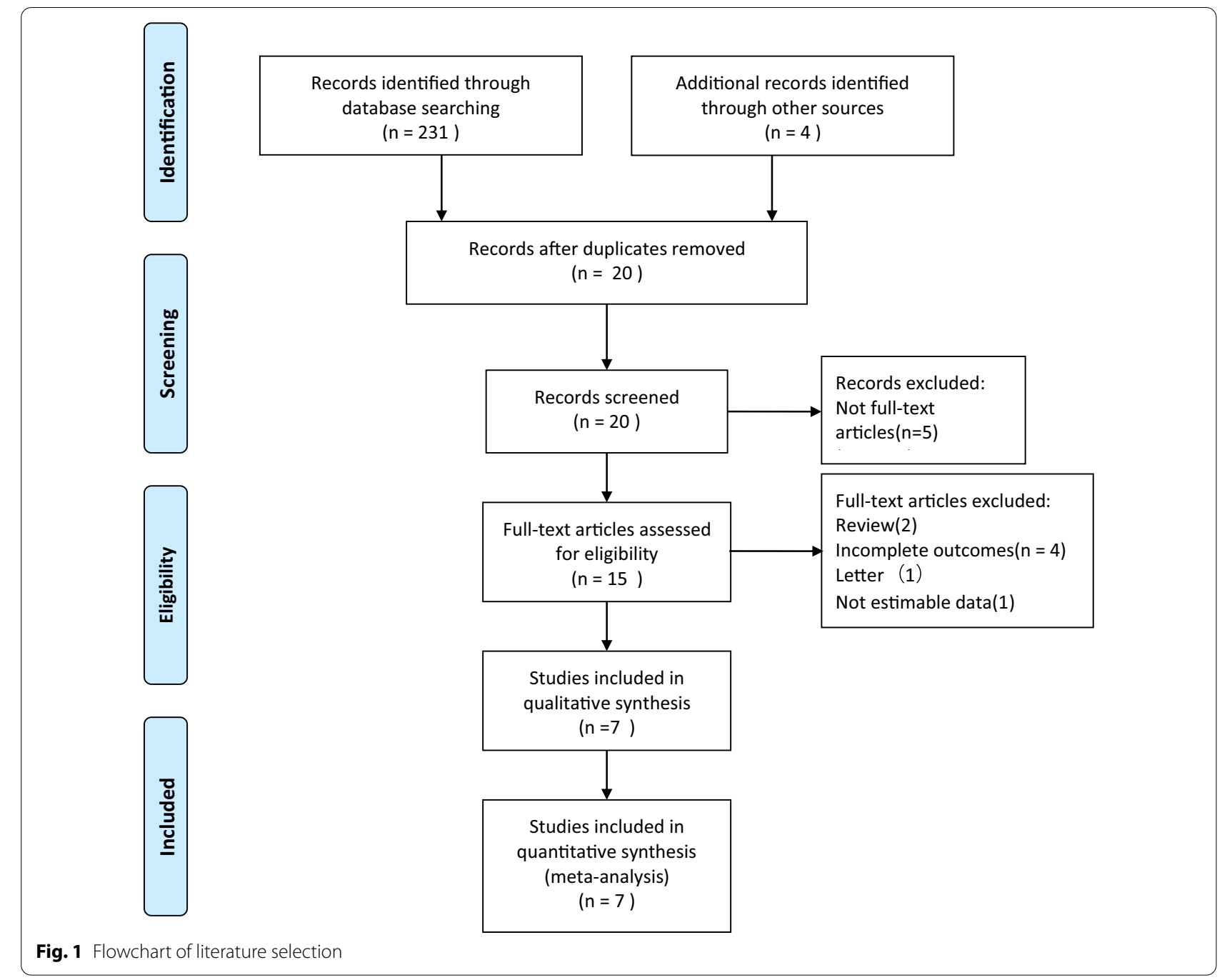

al records identified through other sources $(n=4)$

studies [13]. NOS allocates a maximum of 9 points according to the quality of the selection, comparability and outcomes of the cohort study populations. Study quality was defined as poor (0-3), fair (4-6) or good (7-9). The quality of the included cohort studies is presented in Table 1.

\section{Statistical analysis}

Statistical analyses were performed using Review Manager Version 5.3 (RevMan, The Cochrane Collaboration, Oxford, UK). Odds ratio (OR) with 95\% confidence intervals (CIs) was calculated for dichotomous variables. As to the continuous variables, mean difference (MD) and 95\% CI were estimated as the effect result. A random-effect model was used to pool studies with significant heterogeneity, as determined by the Chi-squared test $(P<0.10)$ and inconsistency index $\left(I^{2} \geq 50 \%\right)[14]$. Some of the selected continuous variables were represented by the median (interquartile range). We calculated their mean and standard deviation according to the sample size with an calculator [15] and then performed meta-analysis. A $P$ value $<0.05$ was set as the threshold of statistical significance.

\section{Results}

\section{Study characteristics}

The search strategy identified 235 studies, and the data were from seven cohort studies comprising 22,655 patients (Table 2) [16-22]. The characteristics of the included studies are shown in Table 2. A total of seven eligible studies were published between 2013 and 2021. Among these studies, two studies were conducted in USA, one study was conducted in Singapore, one study was conducted in Germany, one study was conducted in Saudi Arabia, one study was conducted in Korea, one study was conducted in Canada, USA and Saudi Arabia. Six of these studies were single-center studies, and one was multicenter study. The proportion of patients 
Table 1 Quality of the included cohort studies (The Newcastle-Ottawa scale)

\begin{tabular}{|c|c|c|c|c|c|c|c|c|c|}
\hline \multirow[t]{2}{*}{ Study } & \multicolumn{4}{|l|}{ Selection } & \multirow{2}{*}{$\begin{array}{l}\text { Comparability } \\
\text { Comparability } \\
\text { of cohorts on } \\
\text { the basis of } \\
\text { the design or } \\
\text { analysis }\end{array}$} & \multicolumn{3}{|l|}{ Outcome } & \multirow[b]{2}{*}{$\begin{array}{l}\text { Total } \\
\text { score }\end{array}$} \\
\hline & $\begin{array}{l}\text { Representativeness } \\
\text { of the exposed } \\
\text { cohort }\end{array}$ & $\begin{array}{l}\text { Selection } \\
\text { of the non- } \\
\text { exposed } \\
\text { cohort }\end{array}$ & $\begin{array}{l}\text { Ascertainment of } \\
\text { exposure }\end{array}$ & $\begin{array}{l}\text { Demonstration } \\
\text { that outcome of } \\
\text { interest was not } \\
\text { present at the } \\
\text { start of study }\end{array}$ & & $\begin{array}{l}\text { Assessment of } \\
\text { outcome }\end{array}$ & $\begin{array}{l}\text { Was } \\
\text { follow-up } \\
\text { long } \\
\text { enough for } \\
\text { outcomes } \\
\text { to occur }\end{array}$ & $\begin{array}{l}\text { Adequacy } \\
\text { of follow-up } \\
\text { of cohorts }\end{array}$ & \\
\hline $\begin{array}{l}\text { Phua et al. } \\
\text { [16] }\end{array}$ & H & स & th & th & 论该 & H & ฟ & th & 9 \\
\hline $\begin{array}{l}\text { Bast et al. } \\
\text { [17] }\end{array}$ & 访 & से & 光 & 类 & 访 & मे & 光 & 光 & 8 \\
\hline $\begin{array}{c}\text { Easaw et al. } \\
\text { [18] }\end{array}$ & 访 & 光 & 光 & 出 & 议资 & 访 & 僁 & 光 & 9 \\
\hline $\begin{array}{l}\text { Kethireddy } \\
\text { et al. [19] }\end{array}$ & 放 & 光 & 光 & 为 & 诂谈 & 光 & 光 & 光 & 9 \\
\hline $\begin{array}{l}\text { Sigakis et al. } \\
{[20]}\end{array}$ & 论 & 幽 & th & H & 论访 & H & H & th & 9 \\
\hline $\begin{array}{l}\text { Hazwani } \\
\text { et al. [21] }\end{array}$ & H & स & th & th & 次 & H & 次 & - & 7 \\
\hline $\begin{array}{l}\text { Kim et al. } \\
\text { [22] }\end{array}$ & 诂 & 光 & th & 光 & 论该 & 光 & 光 & 光 & 9 \\
\hline
\end{tabular}

Table 2 The basic characteristics of studies included in meta-analysis

\begin{tabular}{|c|c|c|c|c|c|c|c|c|}
\hline \multirow[t]{2}{*}{ Author } & \multirow[t]{2}{*}{ Year } & \multirow[t]{2}{*}{ Country } & \multirow[t]{2}{*}{ Study period } & \multirow{2}{*}{$\begin{array}{l}\text { All-cause } \\
\text { mortality }\end{array}$} & \multirow[t]{2}{*}{ Study design } & \multicolumn{3}{|c|}{ No. of patients } \\
\hline & & & & & & Total & Culture negative & Culture positive \\
\hline Phua et al. [16] & 2013 & Singapore & 2004-2009 & Hospital & $\begin{array}{l}\text { Single-center, pro- } \\
\text { spective cohort } \\
\text { study }\end{array}$ & 1001 & 415 & 586 \\
\hline Bast et al. [17] & 2015 & Germany & 2009-2014 & 28-day & $\begin{array}{l}\text { Single-center, } \\
\text { retrospective } \\
\text { cohort study }\end{array}$ & 584 & 288 & 296 \\
\hline Easaw et al. [18] & 2017 & USA & $\begin{array}{l}\text { Apr. 2016-Dec. } \\
2016\end{array}$ & All-cause & $\begin{array}{l}\text { Single-center, } \\
\text { retrospective } \\
\text { cohort study }\end{array}$ & 80 & 42 & 38 \\
\hline $\begin{array}{l}\text { Kethireddy et al. } \\
\text { [19] }\end{array}$ & 2018 & $\begin{array}{l}\text { Canada, } \\
\text { USA, Saudi } \\
\text { Arabia }\end{array}$ & $\begin{array}{l}\text { Jan. 1997-Dec. } \\
2010\end{array}$ & Hospital & $\begin{array}{l}\text { Multicenter, retro- } \\
\text { spective cohort } \\
\text { study }\end{array}$ & 8670 & 2651 & 6019 \\
\hline Sigakis et al. [20] & 2019 & USA & $\begin{array}{l}\text { Jan. 2007-May } \\
2014\end{array}$ & Hospital & $\begin{array}{l}\text { Single-center, } \\
\text { retrospective } \\
\text { cohort study }\end{array}$ & 10,393 & 9288 & 1105 \\
\hline Hazwani et al. [21] & 2020 & Saudi Arabia & $\begin{array}{l}\text { Apr. 2015-Jan. } \\
2018\end{array}$ & All-cause & $\begin{array}{l}\text { Single-center, } \\
\text { retrospective } \\
\text { cohort study }\end{array}$ & 209 & 179 & 30 \\
\hline Kim et al. [22] & 2021 & Korea & $\begin{array}{l}\text { Jan. 2014-Dec. } \\
2018\end{array}$ & 90-day & $\begin{array}{l}\text { Single-center, } \\
\text { retrospective } \\
\text { cohort study }\end{array}$ & 1718 & 706 & 1012 \\
\hline
\end{tabular}

with culture-positive sepsis or septic shock is about $40.1 \%(9086 / 22655)$. The median percentage of sepsis episodes, which were culture negative, was $49.3 \%$, but there was variability across studies from a minimum of $30.6 \%$ to a maximum of $89.4 \%$ with an interquartile range of $41.1-52.5 \%$.

\section{Primary outcome}

A total of seven studies including 22,655 patients were included, and the all-cause mortality was about $29.2 \%$ (2928/13569 in the culture-negative group and 3690/9086 in the culture-positive group). There was no statistically significant difference in the all-cause mortality between 
two groups $(\mathrm{OR}=0.95 ; 95 \% \mathrm{CI}, 0.88$ to $1.01 ; P=0.12$; $\mathrm{Chi}^{-}{ }^{2}=30.71 ; I^{2}=80 \%$ ) (Fig. 2). A funnel plot was used to assess the publication bias (Fig. 3).

\section{Secondary outcomes}

\section{ICU length of stay}

Four of included studies were analyzed to assess the ICU length of stay (day). There was no statistically significant difference in the ICU length of stay between two groups $\left(\mathrm{MD}=-0.19 ; 95 \% \mathrm{CI},-0.42\right.$ to $0.04 ; P=0.10 ; \mathrm{Chi}^{2}=5.73$; $I^{2}=48 \%$ ) (Fig. 4).

\section{Hospital length of stay}

Three of included studies were analyzed to assess the hospital length of stay (day). The hospital length of stay of culture-positive group was longer than that of the culture-negative group $(\mathrm{MD}=-3.48 ; 95 \% \mathrm{CI},-4.34$ to $-2.63 ; P<0.00001$; Chi- ${ }^{2}=1.03 ; I^{2}=0 \%$ ) (Fig. 5).

\section{Mechanical ventilation requirements}

Four of included studies were analyzed to assess the mechanical ventilation requirements. There was no statistically significant difference in the mechanical

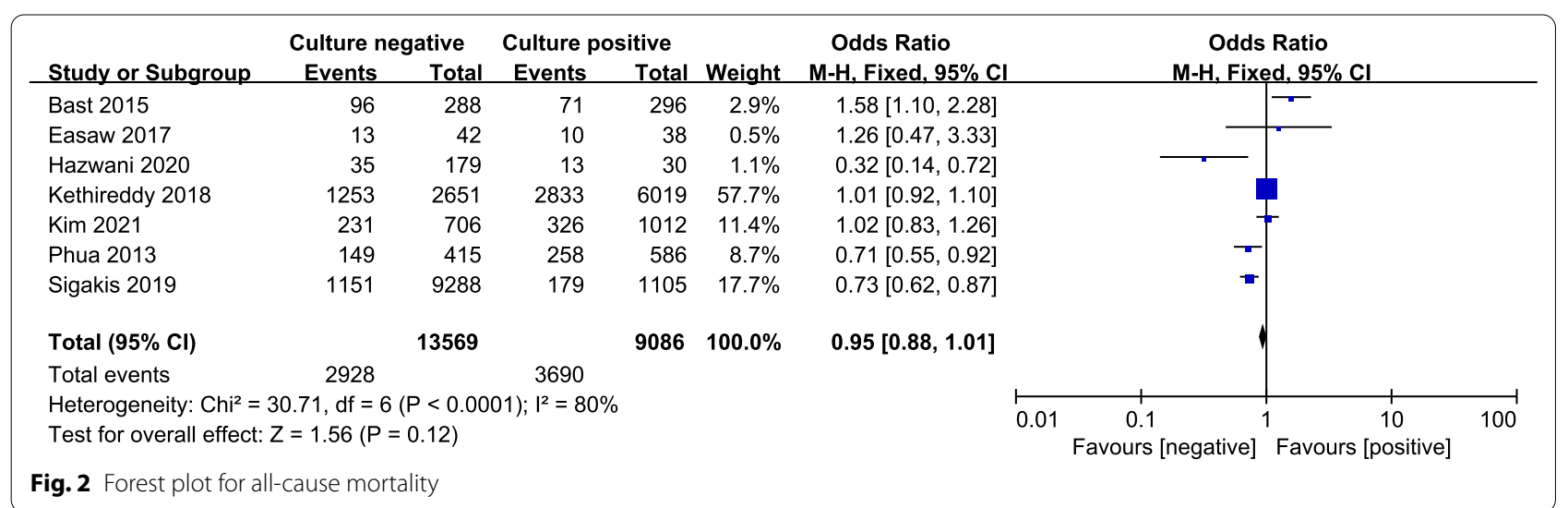

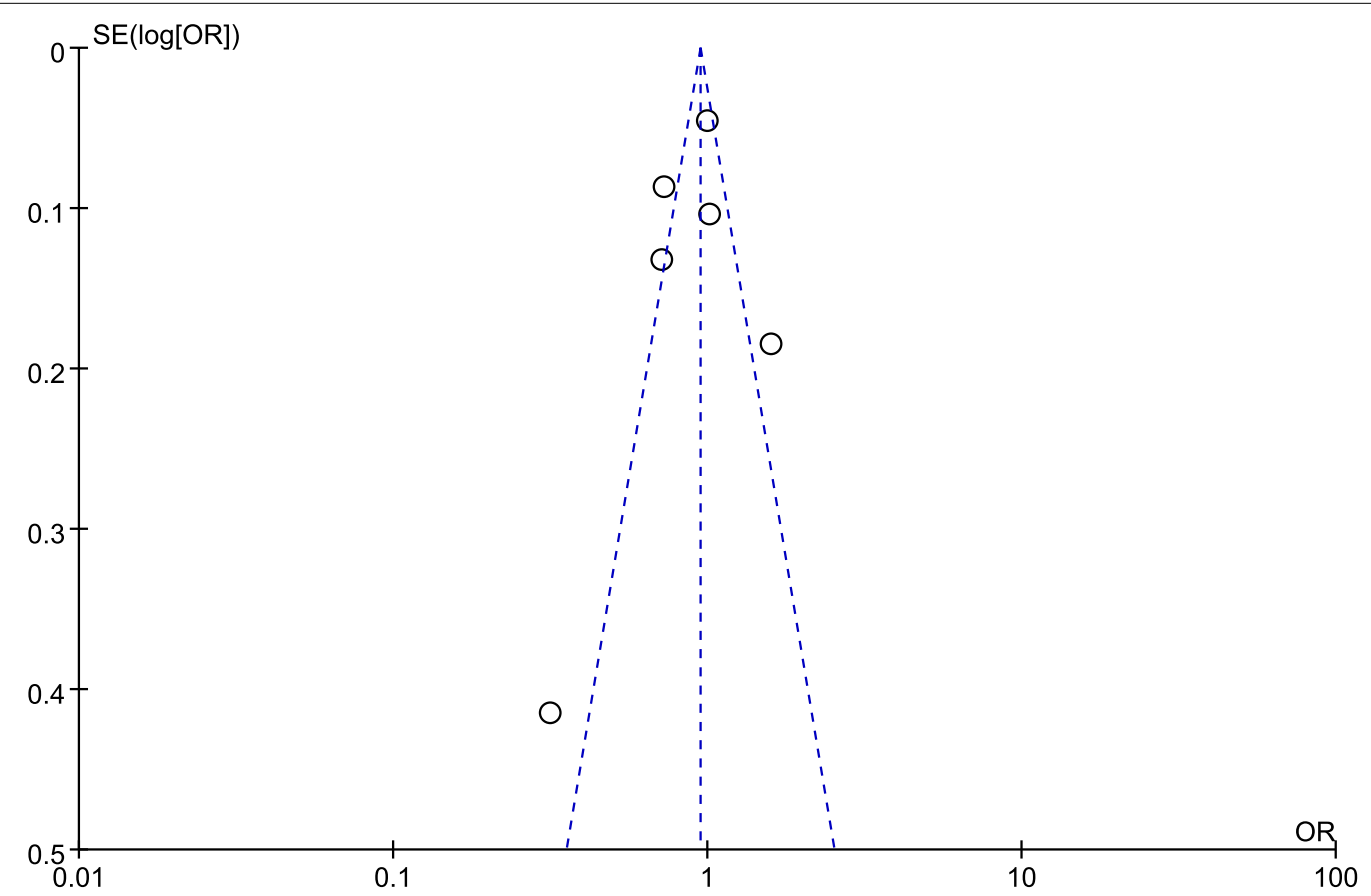

Fig. 3 Funnel plot for all-cause mortality 


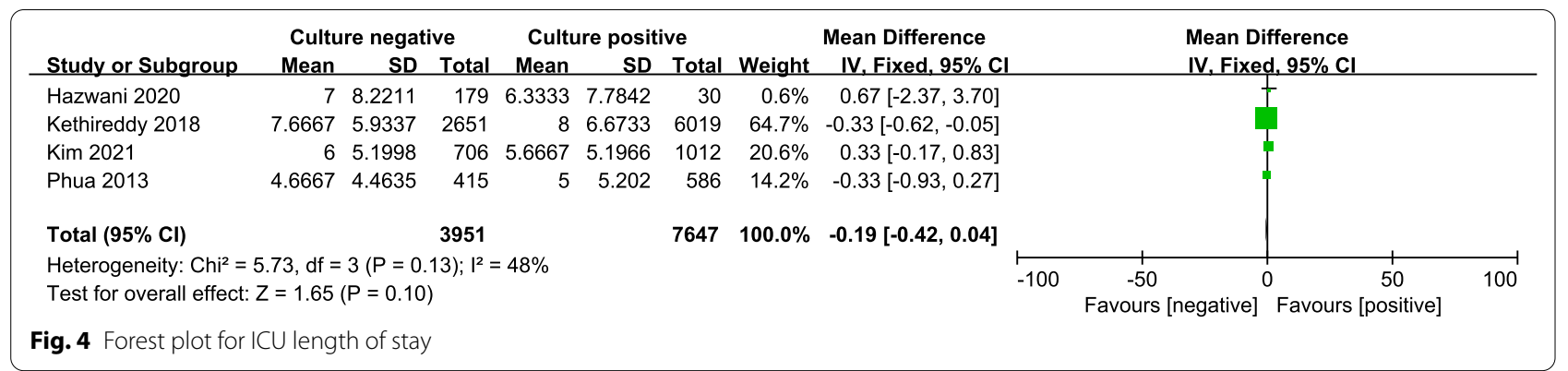

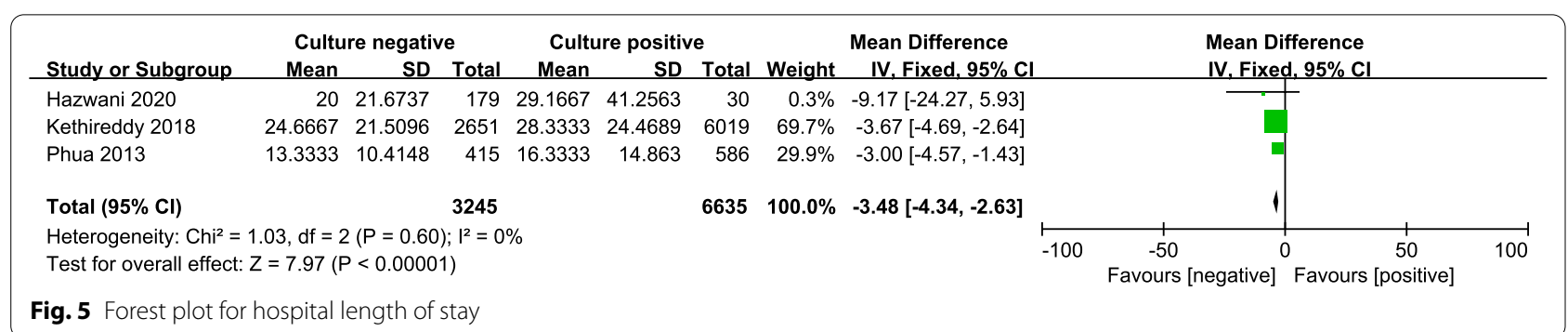

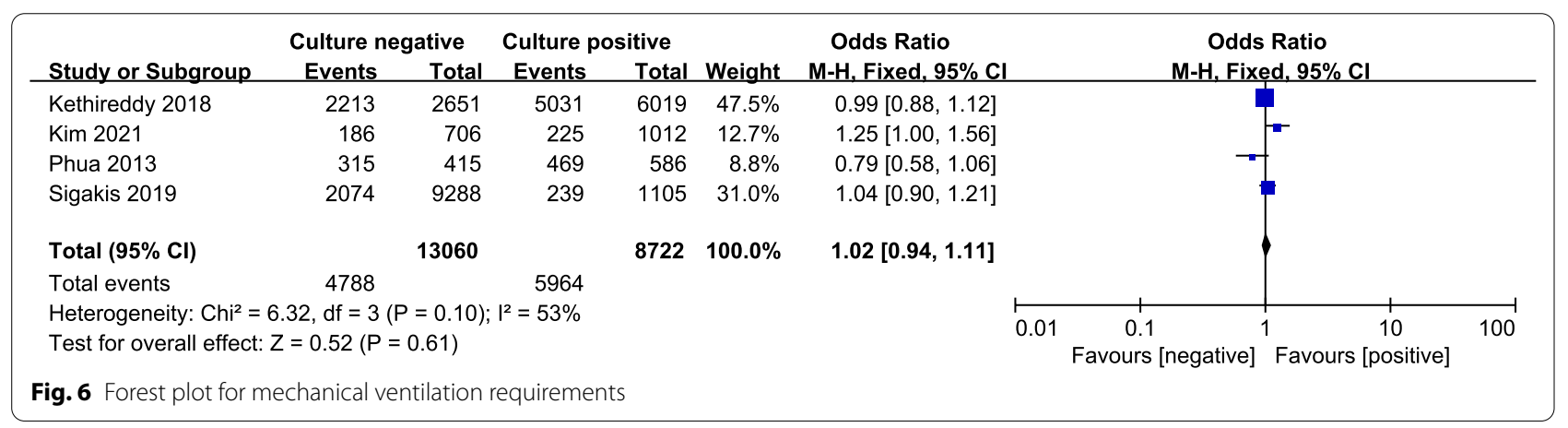

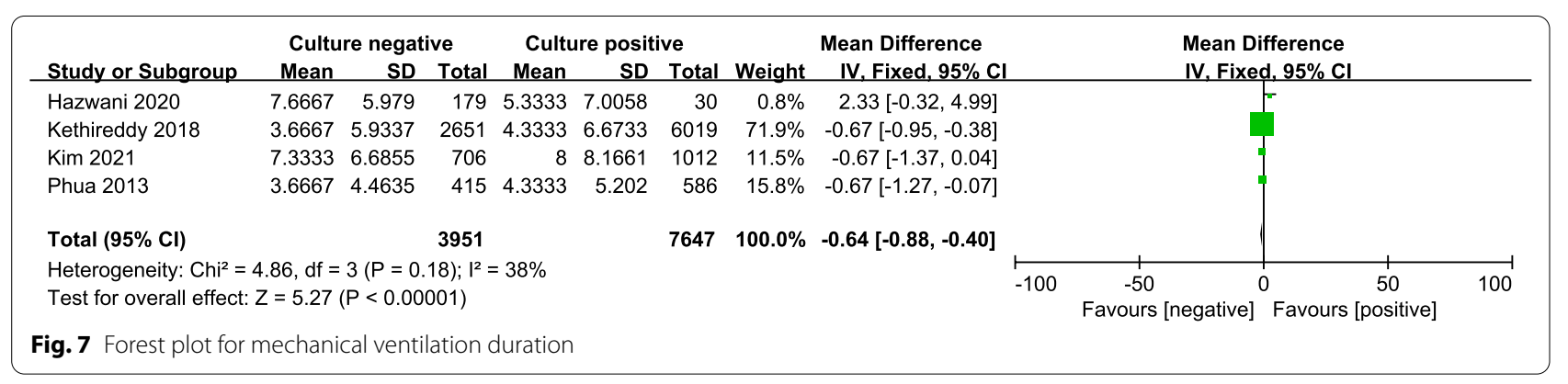

ventilation requirements between two groups $(\mathrm{OR}=1.02$; 95\% CI, 0.94 to $1.11 ; P=0.61 ; \mathrm{Chi}^{2}=6.32 ; I^{2}=53 \%$ ) (Fig. 6).

\section{Mechanical ventilation duration}

Four of included studies were analyzed to assess the mechanical ventilation duration (day). The mechanical ventilation duration of culture-positive group was longer than that of the culture-negative group $(\mathrm{MD}=-0.64 ; 95 \% \mathrm{CI},-0.88$ to $-0.4 ; P<0.00001$; Chi${ }^{2}=4.86 ; I^{2}=38 \%$ ) (Fig. 7). 


\section{Renal replacement requirements}

Three of included studies were analyzed to assess the renal replacement requirements. There was no statistically significant difference in the renal replacement requirements between two groups $(\mathrm{OR}=0.82 ; 95 \% \mathrm{CI}$, 0.67 to $1.01 ; P=0.06$; $\mathrm{Chi}^{-}{ }^{2}=1.21 ; I^{2}=0 \%$ ) (Fig. 8 ).

\section{Discussion}

This systematic review and meta-analysis of seven studies including 22,655 patients compared clinical outcomes of culture-negative and culture-positive sepsis or septic shock patients. We found that only about $40.1 \%$ of patients with sepsis or septic shock had a culture-positive infection. Culture-negative and culture-positive patients with sepsis or septic shock demonstrated a similar mortality. The all-cause mortality was about $29.2 \%$, and we did not identify there was statistically significant difference in the all-cause mortality between culture-negative and culture-positive groups. Clinical picture of laboratory values and vital signs had only fair discrimination between culture-negative and culture-positive patients and that culture-negative and culture-positive patients had mostly similar risk factors for death [20].

Why should patients presenting with a clinical syndrome of sepsis or septic shock have culture-negative infection? First, the patients may have been prescribed empirical antibiotics at local clinics before sepsis or septic shock developed [23]. The most important predictor of culture negativity was receipt of antibiotics within the preceding forty-eight hours [20]. Second, the proportion of sepsis or septic shock cases caused by atypical pathogens, including fungal and viral infections, might be increasing [24, 25]. Microbiologically documented infections may include non-culturable pathogens such as viruses, parasites, and probably fungi. It should be acknowledged that viral/fungal/parasite infections might not be so different from culture-positive infections in terms of effective definitive antimicrobial therapy. Conventional microbiological methods frequently not succeed in identifying a microorganism due to various reasons related to technical issues or intrinsic to the microorganism. Promising researches using polymerase chain reaction (PCR) methods showed that microbial deoxyribonucleic acid (DNA)could be rapidly detected in blood of septic patients and could detect potentially significant fungi and bacteria not retrieved from blood culture [26, 27]. In addition, sputum cultures had a quite low positivity rate, but bronchial aspiration could enhance the possibility of identifying the causative pathogens [28]. Third, many patients having culture-negative sepsis or septic shock might actually have non-infectious causes, such as metabolic disorders, tissue injuries, inflammatory diseases, adverse effects of drugs, malignancies and subarachnoid hemorrhage $[29,30]$.

Besides all-cause mortality, culture-negative and culture-positive patients with sepsis or septic shock demonstrated similar ICU length of stay, mechanical ventilation requirements and renal replacement requirements in our meta-analysis. However, the hospital length of stay and mechanical ventilation duration of culture-positive group were both longer than that of the culture-negative group. These differences are likely due to differences in patient populations, proportions of the sites of infection, and resistance of the bacteria to antibiotics. The longer mechanical ventilation duration and hospital length of stay that we observed in culture-positive patients are likely attributed to the greater occurrence of risk factors, such as older age, higher proportion of malignancies and higher Acute Physiology and Chronic Health Evaluation II (APACHE II) Score. Since sepsis and septic shock are heterogeneous syndromes, the sites of infection were also quite different between the two groups. Previous retrospective studies demonstrated that culture-positive patients with intra-abdominal and lung infections were associated with poor clinical outcomes [31, 32]. However, urinary tract infections were associated with better clinical outcomes than that of the others [33]. We consider that culture negativity might imply susceptibility to the initial antibiotic regimens prescribed, leading to a lesser severity of disease. In addition, the clinical outcomes may

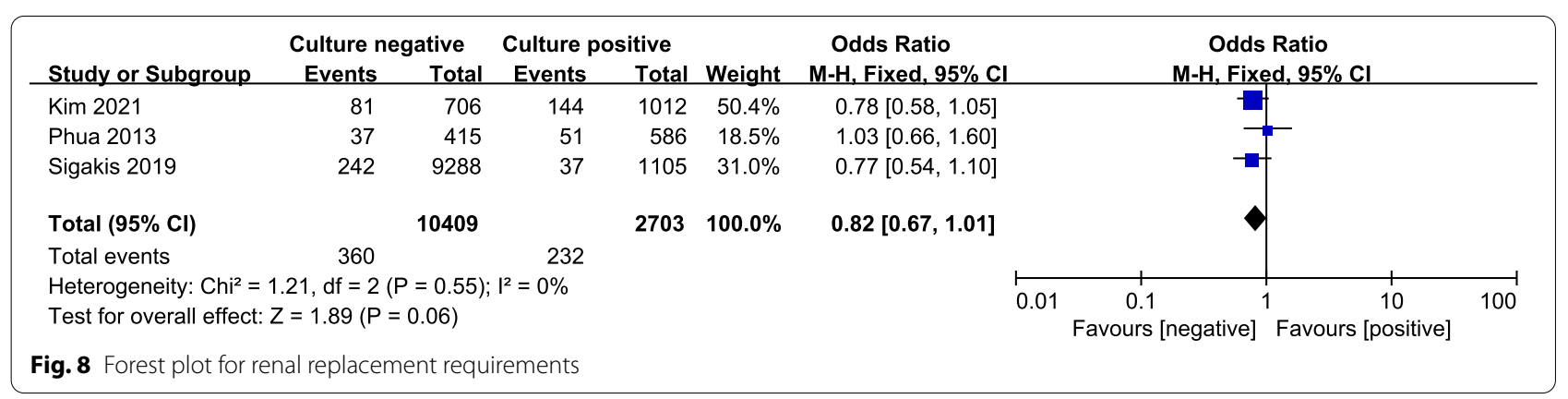


be associated with not only the infection sources but also the management of the sepsis and septic shock.

What are the implications of our meta-analysis's results? The Surviving Sepsis Campaign guidelines recommended early administration of broad-spectrum antibiotics in an effort to improve outcomes in culturenegative or culture-positive sepsis [34]. Every hour of delay in the administration of effective antibiotics from the onset of septic shock will result in increased mortality [35]. Early antimicrobial therapy is deemed appropriate among culture-negative septic patients if they are consistent with national guidelines for the clinical syndrome. Multiplex PCR amplification techniques should be used for the quantification of fungi, viruses and bacteria to elucidate the true-negative and false-negative rates of cultures [36, 37]. If pathogens are not detected, interventional laboratory tests should be used to escalate, continue, narrow or cease antibiotics coupled with a search for non-infectious causes [38].

There are several limitations in our meta-analysis. First, the number of included cohort studies is small. Further large-scale clinical studies should be conducted in order to confirm these results. Second, many of the secondary outcomes such as ICU length of stay, hospital length of stay, mechanical ventilation requirements, mechanical ventilation duration and renal replacement requirements were not included in all of the studies examined in this meta-analysis. Third, there was still substantial heterogeneity among the included cohort studies. Very heterogeneous populations were included in both retrospective and prospective cohort studies. Fourth, suspected source of infection might be the main effect modifiers because some sources of infection have high rates of culture positivity and low rates of mortality (especially urinary tract) and some have low rates of culture positivity and high mortality (especially pulmonary). However, not all of the included studies specified the suspected source of infection. Few of them provided the mortality comparison of culture-negative versus culture-positive infection stratified by source of infection. Fifth, due to the limitation of enrolled studies, our primary outcome all-cause mortality included in-hospital mortality, 28-day mortality and 90-day mortality. As we all understand, these mortality rates are not interchangeable and they are depending on the mortality provided in each included study. Therefore, our results should be interpreted with caution.

\section{Conclusions}

We found that only about $40.1 \%$ of patients with sepsis or septic shock had a culture-positive infection. Culture positivity or negativity was not associated with mortality of sepsis or septic shock patients. Early antimicrobial therapy is deemed appropriate among culture-negative septic patients if they are consistent with national guidelines for the clinical syndrome. Furthermore, culturepositive septic patients had similar ICU length of stay, mechanical ventilation requirements and renal replacement requirements as those culture-negative patients. The hospital length of stay and mechanical ventilation duration of culture-positive septic patients were both longer than that of the culture-negative patients. Further large-scale studies are still required to confirm these results.

\section{Abbreviations \\ Sepsis-3: The Third International Consensus Definitions for Sepsis and Septic Shock; MAP: Mean arterial pressure; ICU: Intensive care unit; PRISMA: Preferred Reporting Items for Systematic Reviews and Meta-Analyses; NOS: Newcas- tle-Ottawa scale; OR: Odds ratio; Cl: Confidence interval; PCR: Polymerase chain reaction; DNA: Deoxyribonucleic acid; APACHE II: Acute Physiology and Chronic Health Evaluation II.}

\section{Acknowledgements}

Not applicable.

\section{Authors' contributions}

YL searched the scientific literature and drafted the manuscript. JG and HY contributed to conception, design and data interpretation. $\mathrm{HL}$ and $\mathrm{YS}$ helped to collect the data and performed statistical analyses. DZ contributed to conception, design, data interpretation, manuscript revision for critical intellectual content and supervision of the study. All authors read and approved the manuscript.

\section{Funding}

This work was supported by the Liquid Therapy Research Fund of China Primary Health Care Foundation (YLGX-ZZ-2020008).

Availability of data and materials

All data generated or analyzed during this study are included in this published article.

\section{Declarations}

Ethical approval and consent to participate Not applicable.

\section{Consent for publication}

Not applicable.

\section{Competing interests}

The authors declare that they have no competing interests.

Received: 7 February 2021 Accepted: 30 April 2021

Published online: 08 May 2021

References

1. Rudd KE, Johnson SC, Agesa KM, Shackelford KA, Tsoi D, Kievlan DR, Colombara DV, Ikuta KS, Kissoon N, Finfer S, et al. Global, regional, and national sepsis incidence and mortality, 1990-2017: analysis for the Global Burden of Disease Study. Lancet. 2020;395(10219):200-11.

2. Leligdowicz A, Dodek PM, Norena M, Wong H, Kumar A, Kumar A, Cooperative Antimicrobial Therapy of Septic Shock Database Research Group. Association between source of infection and hospital mortality in patients who have septic shock. Am J Respir Crit Care Med. 2014;189(10):1204-13. 
3. Liu V, Escobar GJ, Greene JD, Soule J, Whippy A, Angus DC, Iwashyna TJ. Hospital deaths in patients with sepsis from 2 independent cohorts. JAMA. 2014;312(1):90-2

4. Seymour CW, Gesten F, Prescott HC, Friedrich ME, Iwashyna TJ, Phillips GS, Lemeshow S, Osborn T, Terry KM, Levy MM. Time to treatment and mortality during mandated emergency care for sepsis. N Engl J Med. 2017;376(23):2235-44.

5. Singer M, Deutschman CS, Seymour CW, Shankar-Hari M, Annane D, Bauer M, Bellomo R, Bernard GR, Chiche JD, Coopersmith CM, et al. The third international consensus definitions for sepsis and septic shock (Sepsis-3). JAMA. 2016;315(8):801-10.

6. Rhodes A, Evans LE, Alhazzani W, Levy MM, Antonelli M, Ferrer R, Kumar A, Sevransky JE, Sprung CL, Nunnally ME, et al. Surviving Sepsis Campaign: international guidelines for management of sepsis and septic shock: 2016. Intensive Care Med. 2017;43(3):304-77.

7. Kumar A, Ellis P, Arabi Y, Roberts D, Light B, Parrillo JE, Dodek P, Wood G, Kumar A, Simon D, Cooperative Antimicrobial Therapy of Septic Shock Database Research Group, et al. Initiation of inappropriate antimicrobial therapy results in a fivefold reduction of survival in human septic shock. Chest. 2009;136(5):1237-48.

8. Rannikko J, Syrjänen J, Seiskari T, Aittoniemi J, Huttunen R. Sepsis-related mortality in 497 cases with blood culture-positive sepsis in an emergency department. Int J Infect Dis. 2017;58:52-7.

9. de Prost N, Razazi K, Brun-Buisson C. Unrevealing culture-negative severe sepsis. Crit Care. 2013;17(5):1001.

10. Rangel-Frausto MS, Pittet D, Costigan M, Hwang T, Davis CS, Wenzel RP. The natural history of the systemic inflammatory response syndrome (SIRS). A prospective study. JAMA. 1995;273(2):117-23.

11. Moher D, Liberati A, Tetzlaff J, Altman DG, PRISMA Group. Preferred reporting items for systematic reviews and meta-analyses: the PRISMA Statement. Open Med. 2009;3(3):e123-30.

12. Gupta S, Sakhuja A, Kumar G, McGrath E, Nanchal RS, Kashani KB. Culture-negative severe sepsis: nationwide trends and outcomes. Chest. 2016;150(6):1251-9.

13. Wells GA, Shea BJ, O'connell D, et al. The Newcastle-Ottawa Scale (NOS) for assessing the quality of non-randomized studies in meta-analysis. Appl Eng Agric. 2014;18:727-34.

14. Biggerstaff BJ, Jackson D. The exact distribution of Cochran's heterogeneity statistic in one-way random effects meta-analysis. Stat Med. 2008;27(29):6093-110.

15. Wan X, Wang W, Liu J, Tong T. Estimating the sample mean and standard deviation from the sample size, median, range and/or interquartile range BMC Med Res Methodol. 2014;14:135.

16. Phua J, Ngerng W, See K, Tay C, Kiong T, Lim H, Chew M, Yip H, Tan A, Khalizah $\mathrm{H}$, et al. Characteristics and outcomes of culture-negative versus culture-positive severe sepsis. Crit Care. 2013;17(5):R202.

17. Bast J, Scheer C, Rehberg S, Fuchs C, Vollmer M, Balau V, Kuhn SO, Hahnenkamp K, Gruendling M. Mortality of blood-culture-positive vs. bloodculture-negative patients with severe sepsis and septic shock. Infection. 2015:43:S58-9.

18. Easaw SM, Kaul V, Gupta J, Alex L, Warshawsky M. Factors affecting mortality and length of stay among patients with culture positive or culture negative severe sepsis. Chest. 2017;152(4):A412.

19. Kethireddy S, Bilgili B, Sees A, Kirchner HL, Ofoma UR, Light RB, Mirzanejad Y, Maki D, Kumar A, Layon AJ, Cooperative Antimicrobial Therapy of Septic Shock (CATSS) Database Research Group, et al. Culture-negative septic shock compared with culture-positive septic shock: a retrospective cohort study. Crit Care Med. 2018;46(4):506-12.

20. Sigakis MJG, Jewell E, Maile MD, Cinti SK, Bateman BT, Engoren M. Culture-negative and culture-positive sepsis: a comparison of characteristics and outcomes. Anesth Analg. 2019;129(5):1300-9.

21. Hazwani TR, Kazzaz YM, Alsugheir S, Aldelaijan S, Alsugheir F, Alali H, Alsadoon A, Alhamwah M, Alsubaiel S, Alomar B, et al. Association between culture-negative versus culture-positive sepsis and outcomes of patients admitted to the pediatric intensive care unit. Cureus. 2020;12(8):e9981.
22. Kim JS, Kim YJ, Kim WY. Characteristics and clinical outcomes of culturenegative and culture-positive septic shock: a single-center retrospective cohort study. Crit Care. 2021;25(1):11.

23. Scheer CS, Fuchs C, Gründling M, Vollmer M, Bast J, Bohnert JA, Zimmermann K, Hahnenkamp K, Rehberg S, Kuhn SO. Impact of antibiotic administration on blood culture positivity at the beginning of sepsis: a prospective clinical cohort study. Clin Microbiol Infect. 2019;25(3):326-31.

24. Lin GL, McGinley JP, Drysdale SB, Pollard AJ. Epidemiology and immune pathogenesis of viral sepsis. Front Immunol. 2018:9:2147.

25. Delaloye J, Calandra T. Invasive candidiasis as a cause of sepsis in the critically ill patient. Virulence. 2014;5(1):161-9.

26. Bloos F, Sachse S, Kortgen A, Pletz MW, Lehmann M, Straube E, Riedemann NC, Reinhart K, Bauer M. Evaluation of a polymerase chain reaction assay for pathogen detection in septic patients under routine condition: an observational study. PLOS ONE. 2012;7(9):e46003.

27. Bloos F, Hinder F, Becker K, Sachse S, Mekontso Dessap A, Straube E, Cattoir V, Brun-Buisson C, Reinhart K, Peters G, et al. A multicenter trial to compare blood culture with polymerase chain reaction in severe human sepsis. Intensive Care Med. 2010;36(2):241-7.

28. Koslow M, Epstein Shochet G, Matveychuk A, Israeli-Shani L, Guber A Shitrit D. The role of bacterial culture by bronchoscopy in patients with lung cancer: a prospective study. J Thorac Dis. 2017;9(12):5300-5.

29. Cohen J, Brun-Buisson C, Torres A, Jorgensen J. Diagnosis of infection in sepsis: an evidence-based review. Crit Care Med. 2004;32(11 Suppl):S466-94.

30. Vincent JL, Opal SM, Marshall JC, Tracey KJ. Sepsis definitions: time for change. Lancet. 2013;381(9868):774-5.

31. Labelle AJ, Arnold H, Reichley RM, Micek ST, Kollef MH. A comparison of culture-positive and culture-negative health-care-associated pneumonia. Chest. 2010;137(5):1130-7.

32. Karvellas CJ, Abraldes JG, Zepeda-Gomez S, Moffat DC, Mirzanejad Y, Vazquez-Grande G, Esfahani EK, Kumar A, Cooperative Antimicrobial Therapy of Septic Shock (CATSS) Database Research Group. The impact of delayed biliary decompression and anti-microbial therapy in 260 patients with cholangitis-associated septic shock. Aliment Pharmacol Ther. 2016;44(7):755-66

33. Abe T, Ogura H, Kushimoto $S$, Shiraishi A, Sugiyama T, Deshpande GA, Uchida M, Nagata I, Saitoh D, Fujishima S, JAAM FORECAST group, et al. Variations in infection sites and mortality rates among patients in intensive care units with severe sepsis and septic shock in Japan. J Intensive Care. 2019;7:28

34. Dellinger RP, Levy MM, Rhodes A, Annane D, Gerlach H, Opal SM, Sevransky JE, Sprung CL, Douglas IS, Jaeschke R, Surviving Sepsis Campaign Guidelines Committee including the Pediatric Subgroup, et al. Surviving sepsis campaign: international guidelines for management of severe sepsis and septic shock: 2012. Crit Care Med. 2013;41(2):580-637.

35. Kumar A, Roberts D, Wood KE, Light B, Parrillo JE, Sharma S, Suppes R, Feinstein D, Zanotti S, Taiberg L, et al. Duration of hypotension before initiation of effective antimicrobial therapy is the critical determinant of survival in human septic shock. Crit Care Med. 2006;34(6):1589-96.

36. Dark PM, Dean P, Warhurst G. Bench-to-bedside review: the promise of rapid infection diagnosis during sepsis using polymerase chain reactionbased pathogen detection. Crit Care. 2009;13(4):217.

37. Lisboa T, Waterer G, Rello J. We should be measuring genomic bacterial load and virulence factors. Crit Care Med. 2010;38(10 Suppl):S656-62.

38. Heenen S, Jacobs F, Vincent JL. Antibiotic strategies in severe nosocomial sepsis: why do we not de-escalate more often? Crit Care Med. 2012;40(5):1404-9.

\section{Publisher's Note}

Springer Nature remains neutral with regard to jurisdictional claims in published maps and institutional affiliations. 